\title{
Composition and Distribution of Pythium Communities in Wheat Fields in Eastern Washington State
}

\author{
T. C. Paulitz and K. Adams
}

USDA-ARS, Root Disease and Biological Control Lab, Washington State University, Pullman 99164-6430.

Accepted for publication 12 March 2003.

\begin{abstract}
Paulitz, T. C., and Adams, K. 2003. Composition and distribution of Pythium communities in wheat fields in eastern Washington state. Phytopathology 93:867-873.

Pythium spp. were isolated from a mixture of soil and roots collected from 80 wheat fields in eastern Washington in the summer of 2000 from an area encompassing approximately $27,000 \mathrm{~km}^{2}$. These sites covered a range of soil textures (coarse to fine, silty loess), average annual precipitation (200 to $600 \mathrm{~mm}$ ), and average annual temperatures ( 7 to $11^{\circ} \mathrm{C}$ ). Soil type and annual precipitation run in an east-west gradient, while temperature has a north-south gradient. Species were identified using classical methods and by sequencing the internal transcribed spacer (ITS)-1 region of the rDNA and comparing these sequences to a database from a worldwide collection of Pythium spp. The species with the highest frequency of occurrence among all the sites were $P$. abappressorium $\mathrm{sp}$. nov. (A) (50\%), P. rostratum (R) (40\%), P. debaryanum (D) $(37.5 \%), P$. heterothallicum $(\mathrm{H})(33.7 \%)$, P. oligandrum $(\mathrm{O})(31.2 \%)$, an unidentified $P$. sp. (aff. echinulatum) (E) (25\%), and P. ultimum (U) (18\%). P. intermedium, $P$. irregulare, $P$. paroecandrum, $P$. sylvaticum, $P$. dissimile, and $P$. dissoticum were isolated at a low frequency. From one to six species were isolated at each site, and there were 46 different species

combinations detected. The species presence/absence data from all sites were analyzed with Jaccard's similarity coefficient hierarchical cluster analysis. Six communities were identified (species within each community designation in order of frequency among the sites within the community)-AD, AOU, AR, DEH, HE, and RU. In general, P. abappressorium was evenly distributed over all zones. AOU was more prevalent in zones with lower precipitation and coarser soil, while DEH and HE were associated with zones with higher precipitation and finertextured soils on the basis of comparison of frequency distributions with the expected distribution over all the sites. The RU community was more prevalent in higher temperature zones. Canonical correspondence analysis was performed to examine the relationship between species and environmental variables. Soil type and precipitation were highly correlated with each other and with axis 1 , which separated $P$. ultimum and $P$. abappressorium (lower variable values) from $P$. heterothallicum (higher variable values). Axis 2 and 3 were most correlated with temperature, and these axes separated $P$. oligandrum (higher value) from $P$. debaryanum (lower value) and $P$. ultimum- $P$. rostratum from the other species. The results suggest that Pythium species composition, distributions, and associations on a given crop may be influenced by environmental factors at a mesoscale level (100 to 1,000,000 ha).
\end{abstract}

Pythium root rot is an important yield-limiting disease on wheat and barley produced under dryland conditions in eastern Washington $(5,6)$. This disease is characterized by a reduction in seedling emergence, smaller and distorted first true leaves, plant stunting, reduced tillering, loss of fine feeder roots, and lower yields. Because of the ubiquitous nature of Pythium spp. in most soils, Cook and Veseth (7) have referred to this disease as the "common cold" of wheat. Pythium spp. have also been reported to be a problem on wheat and barley in Australia (35) and the United Kingdom (46).

Despite the prevalence of this genus on wheat, little is known about the composition and distribution of species over the diverse habitats characterized by variable edaphic and environmental conditions in eastern Washington. This area is characterized by deep wind-deposited (loess) soils, a range in rainfall from 220 to 650 $\mathrm{mm}$ per year, and rolling hills in the most eastern part. Twentynine species of Pythium have been reported on wheat worldwide (Fungus-Host Distributions, Systematic Botany and Mycology Laboratory, USDA Agricultural Research Service, Beltsville, MD) and 19 have been reported in North America (12). Chamswarng and Cook (4) isolated 10 species of Pythium and two unidentified Pythium isolates, but they only sampled from fields in eastern Whitman County, WA and adjacent western Latah County, ID.

Corresponding author: T. C. Paulitz; E-mail address: paulitz@wsu.edu

Publication no. P-2003-0506-02R

This article is in the public domain and not copyrightable. It may be freely reprinted with customary crediting of the source. The American Phytopathological Society, 2003.
Pythium spp. can be difficult to identify using morphological characteristics. Many species are asexual or heterothallic and do not form sexual structures in culture. Within the last 10 years, molecular techniques have been used for the identification, taxonomy, and phylogeny of Pythium spp., especially techniques based on the internal transcribed spacer (ITS) region of the ribosomal DNA $(21,24,25,36,47)$. Paulitz et al. (37) described a new species of Pythium from wheat in eastern Washington based on morphological traits and unique sequence of the ITS region.

The influences of environmental factors on Pythium communities and species have not been examined in detail at the mesoscale level. Some studies $(13,14)$ have examined soil factors associated with suppression of Pythium, such as soil $\mathrm{C}, \mathrm{N}$, and microbial activity. Other studies have examined correlations among selected environmental factors and frequency of Pythium species at a few field sites (23). In this study, we attempted to characterize the distribution of Pythium species over a range of soil and climatic zones over eastern Washington. Because of the topography and geography of this region, there is a gradient of soil type, annual precipitation, and annual temperature across the dryland wheatgrowing area from central Washington to the Idaho border.

Multivariate statistics are widely used in ecology (20) and offer tools to examine the relationships among multiple environmental variables and species composition. For instance, these techniques have been used in soil ecology to identify factors that influence populations of soil microorganisms or to characterize populations of microbes in response to different soil management treatments, such as conventional and reduced tillage. These techniques include principal components analysis $(34,40)$, discriminant analysis 
(11), and canonical discriminant analysis (14). One recent technique that has proven useful in plant and insect ecology but has not been applied in plant pathology studies is canonical correspondence analysis (CCA) (41). CCA is a type of direct gradient analysis, which examines the relationship between two sets of variables by constructing axes based on linear combinations of variables. Variables can then be ordinated on a two-dimensional graph. This technique is similar to principal components analysis and uses an eigenanalysis of a correlation matrix. This technique has been used to compare microbial populations (17) and soil fauna (10) in conventional and reduced-input farming systems and to compare composition of nematodes and fungal populations on the roots of a sand dune grass (43).

The purpose of this paper was to survey Pythium communities from wheat fields over a range of soil and climatic zones in eastern Washington. Communities were defined based on assemblages of species within and among sites. Species were identified using classical and molecular techniques, and multivariate techniques were used to examine species associations and correlations of communities with soil type, precipitation, and temperature across this region.

\section{MATERIALS AND METHODS}

Collection and maintenance of isolates. Soil and root samples were collected from 80 wheat fields representing over $27,000 \mathrm{~km}^{2}$ in eastern Washington from July to August 2000 (Fig. 1). Soil from the top 30-cm depth was collected with a shovel within rows of wheat from three sites in each field for a total of approximately $2 \mathrm{~kg}$. Samples were stored in plastic bags at $4^{\circ} \mathrm{C}$ until processing. Three 20-g samples containing roots and soils were removed from each bag, placed in 15-cm petri dishes, rewetted with 2 to $3 \mathrm{ml}$ of water (approximate field capacity), and incubated at $22^{\circ} \mathrm{C}$ for 24 to $48 \mathrm{~h}$. Plates were flooded with distilled water, and 10 grass clippings (approximately $1 \mathrm{~cm}$ in length) (Poa pratensis L.) were floated on the water. After 24 to $36 \mathrm{~h}$ incubation, the grass clippings were blotted on sterile paper towels and plated on a modified Pythium-selective medium (33) using water agar instead of corn meal agar. Emerging hyphal tips were removed from all colonies 1 day later using a pasteur pipette drawn out to a fine tip and plated on water agar. Cultures were also grown on potato dextrose agar (PDA) and V8 agar and later transferred to autoclaved grass clippings in sterile pond water for identifications (42). Cultures were stored at $4^{\circ} \mathrm{C}$ on PDA slants and sterile oat seeds. Pythium species were identified using the keys and descriptions of van der Plaats-Niterinck (42), Dick (8), Matthews (30), Middleton (32), and Waterhouse (48).

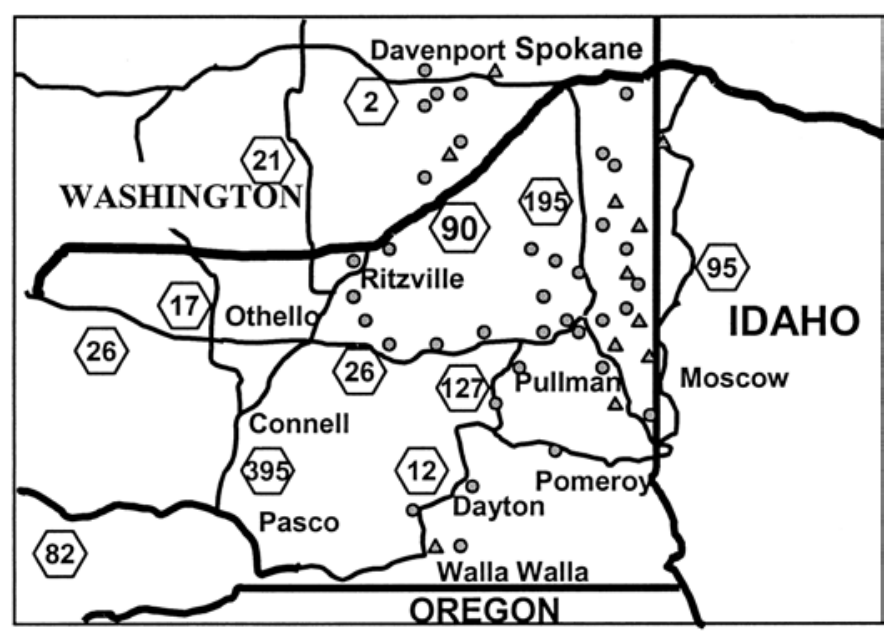

Fig. 1. Map of eastern Washington showing sampling sites. Triangles represent multiple sampling sites.
Extraction, polymerase chain reaction (PCR) amplification, and sequencing of DNA. A random sample of the collection, approximately 200 isolates, was selected for ITS identification. DNA was isolated, amplified, and sequenced according to the methods described in Paulitz et al. (37). Mycelium was grown in potato dextrose broth in $12.5 \times 1.5-\mathrm{cm}$ tubes at room temperature on an orbital shaker at ca. $110 \mathrm{rpm}$. DNA was extracted from mycelium using FastDNA tubes (FastDNA Kit, Bio101, Carlsbad, CA), CLS-Y cell lysis solution, and homogenization in an FP 120 FastPrep Cell Disruptor (Thermo Savant, Holbrook, NY) at speed 4 for $40 \mathrm{~s}$. Samples were then centrifuged at $12,000 \mathrm{rpm}$ for $1 \mathrm{~min}$, the supernatant transferred to $1.5-\mathrm{ml}$ microcentrifuge tubes and mixed with $600 \mu \mathrm{l}$ of binding matrix. After incubation for $5 \mathrm{~min}$ at room temperature, the tubes were centrifuged at $12,000 \mathrm{rpm}$ for $1 \mathrm{~min}$, and the supernatant was discarded. Pellets were resuspended in 500- $\mu \mathrm{l}$ salt/ethanol wash solution (SEWS)-M and centrifuged at 13,000 rpm for $1 \mathrm{~min}$. After removal of the wash solution, tubes were spun $5 \mathrm{~s}$, and the residual solution was pipetted off before eluting DNA. The matrix was resuspended in $100-\mu 1$ DNA elution solution (DES) and incubated for $3 \mathrm{~min}$ at room temperature. Samples were then centrifuged at $12,000 \mathrm{rpm}$ for $1 \mathrm{~min}$, and the supernatant was transferred to $0.5-\mathrm{ml}$ microcentrifuge tubes.

DNA was amplified with ITS-1 primers UN-UP18542 and OOM-LO5.8S47B and ITS-2 primers OOM-UP5.8S01 and PYLO28S22 (24) using the reaction mixtures and cycling conditions of Paulitz et al. (37). PCR products were treated with ExoSAP-IT (United States Biochemical, Cleveland, $\mathrm{OH}$ ) and reamplified with Big Dye Mix (ABI-Prism, Foster City, CA). After cycling, the sequencing reaction was cleaned over a Sephadex G-50 fine mini spin column, dried in a speed-vac, resuspended in loading dye, and run on an ABI 377 sequencer. The ITS-1 DNA sequences were compared using BLAST with over 1,200 sequences from a worldwide collection that included types and neotypes of most species of Pythium (C. A. Lévesque, unpublished data).

Mapping of sample sites and characterization of environmental zones. Each sample site was mapped on a 1:150,000 topographical map and later on a U.S. Geological Survey (USGS) 1:24,000 topographical map using Maptech software (Maptech, Andover, MA). Each sample site was located on the appropriate maps and classified according to soil type, precipitation, and temperature zone. The soil type of each site was classified using the general soil map of Washington (3). Typically, the soils were deep, loessial, silty soils that have been wind-deposited over thousands of years. Soil texture varied along a generally east-west gradient, with the coarsest soils in the west (L2, dry, coarse-silty, loessial soil) and the finer soils in the east (L5, fine-silty, loessial soil). The soils had evolved under shrub-steppe vegetation in the west and under meadow-steppe vegetation in the east. L4 and L5 soils were also humus-rich. L2 soil is an aridic/mesic soil and L3, L4, and L5 are xeric/mesic soils. All soil series are classified as Mollisols. Average annual precipitation and average annual temperature zones were assigned from interpolated maps (28). These maps were derived using geostatistical methods of squared inverse distance weighing (IDW) to interpolate weather data (30-year averages) from weather stations to a regular grid of points $20 \mathrm{~km}$ apart. There were four annual precipitation zones (200 to 300, 300 to 400,400 to 500 , and 500 to $600 \mathrm{~mm}$ ) and five average annual temperature zones ( 7 to 8,8 to 9,9 to 10,10 to 11 , and 11 to $12^{\circ} \mathrm{C}$ ).

Statistical analyses. Because the baiting technique was not quantitative within a sample, only the presence or absence of each species was recorded for each site. The frequency of occurrence of each species was calculated as the number of sites that contained that species/total number of sites $\times 100$. Species richness of each site was determined as the total number of Pythium species detected at each site. Relationships between species richness and environmental variables were evaluated by regression analysis (JMP Version 4.0, SAS Institute, Cary, NC). 
To group species into communities, hierarchical cluster analysis was performed using Jaccard's similarity coefficient calculated for each possible pairwise combination of sampling sites (27), such that $C_{j}=j /(a+b+j)$, where $j=$ the number of species in common to a pair of sampling sites $\mathrm{A}$ and $\mathrm{B}, a=$ the number of species unique to sample site $\mathrm{A}$, and $b=$ the number of species unique to sample site B. This index, also known as Jaccard's similarity index, is widely used in ecology with presence-absence data $(26,45)$. Two sites will be more similar if they share more species and more dissimilar if more species are unique to one site. Dendrograms were constructed using the unweighted pair group method using arithmetic averages (UPGMA) method (38).

CCA was used to examine the relationship among species and environmental factors (41). Two matrices were used. The species matrix consisted of the species composition at each of the 80 sites, and the environmental matrix was composed of the three environmental variables as ordinal data at each site (soil class 2-5, precipitation class 2-5, and temperature class 7-11). A weighted correlation was calculated among the three environmental variables. The statistical significance of eigenvalues and speciesenvironment correlations within each axis were tested with a Monte Carlo simulation of 1,000 runs. The resulting $P$ value was computed as the proportion of randomized runs with an eigenvalue greater than or equal to the observed. Cluster analysis and CCA were performed using the PC-ORD software version 4. 20 (MJM Software Design Gleneden Beach, OR).

For each Pythium community identified from the cluster analysis, the median and mean values for each environmental factor were calculated based on all the sites classified in that community. To determine whether the frequency distributions of environmental classes varied among the Pythium communities, the following test was performed. An expected frequency distribution was constructed for each variable based on the total number of sampling sites (80). An observed frequency distribution for each environmental variable was derived for each community based on the sampling sites classified within that community. For example, $61.2 \%$ of the total sample sites were classified in soil L5, $11.2 \%$ in soil L4, 20\% in soil L3, and 7.5\% in soil L2. This would be the expected frequency distribution for the soil variable. The observed and expected frequency distributions were compared using a Kolmogorov-Smirnov test, which calculated a $P$ value from a twotailed Chi-Square approximation (Statistix Version 7, Analytical Software, Tallahassee, FL).

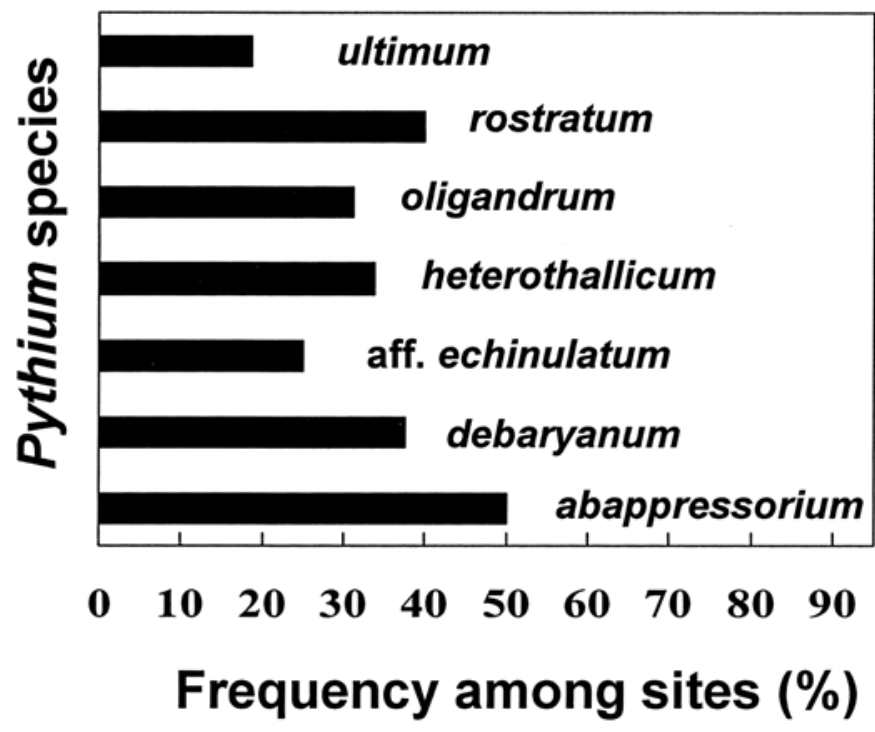

Fig. 2. Frequency of occurrence of Pythium species from 80 sites in eastern Washington.

\section{RESULTS}

Species composition. Fourteen species of Pythium were isolated from the 80 sample sites, from a total of 532 isolates. The most common species among sites were Pythium abappressorium sp. nov. Paulitz \& Mazzola, P. debaryanum Auct. non Hesse, P. heterothallicum Campbell \& Hendrix, P. oligandrum Drechs., $P$. rostratum E.J. Butler, and $P$. ultimum var. ultimum Trow. One unidentified species was found, which formed large liniform sporangia 20 to $32 \mu \mathrm{m}$ in diameter, often in doublets. The colonies of this species formed chrysanthemum patterns on PDA, with a colony growth rate of 5 to $6 \mathrm{~mm}$ per day at $25^{\circ} \mathrm{C}$. Oospores were not formed in single culture, and attempts at mating were not successful. Based on ITS-1 sequences, the closest match was to $P$. echinulatum, and we therefore, assigned the name of Pythium sp. (aff. echinulatum). Seven other species were found at lower frequencies (number of sites in parentheses): P. intermedium de Bary (three), P. irregulare Buisman (four), P. paroecandrum Drechs. (four), P. sylvaticum Campbell \& Hendrix (two), $P$. dissimile Vaartaja (one), P. pleroticum Ito (one), and P. dissoticum Drechs. (one). $P$. dissimile and $P$. pleroticum have not been reported from wheat before. $P$. abappressorium was the most common among sites, isolated from $50 \%$ of the sampled sites (Fig. 2). P. debaryanum, $P$. rostratum, and $P$. heterothallicum were found in 30 to $40 \%$ of the sites. P. ultimum was the least common of this group, being found in only $18 \%$ of the sites. The average species richness over all sites was 2.52 (SD 1.36), range 1-6, median $=2$, and mode $=2$. Species richness was not affected by soil type, precipitation, or temperature.

Pythium communities. Four major communities were identified based on a dendrogram using Jaccard's similarity coefficient (Fig. 3). Within the largest community, all sites contained $P$. abappressorium (Cluster 1). This community could be divided into three subclusters, namely, $P$. abappressorium in association with $P$. debaryanum (Cluster 1A), $P$. abappressorium in association with $P$. oligandrum and $P$. ultimum (Cluster $1 \mathrm{~B}$ ), and $P$. abappressorium in association with $P$. rostratum (Cluster $1 C$ ). The other three main clusters contained $P$. debaryanum in association

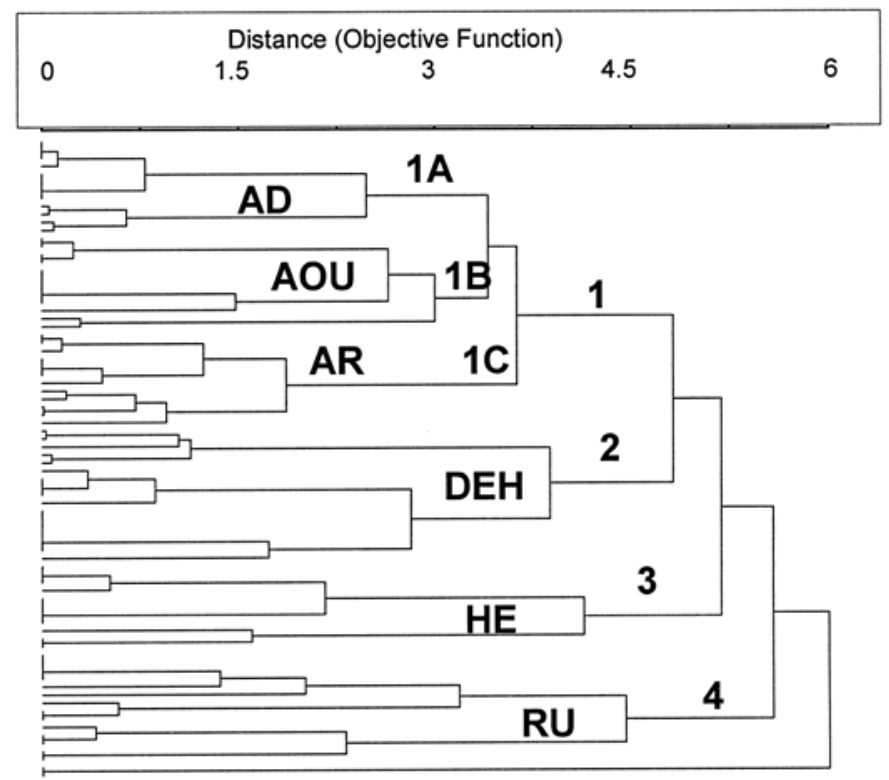

Fig. 3. Cluster analysis of sampling sites based on Pythium species present at each site and pairwise comparisons based on Jaccard's similarity coefficient. Dendogram was constructed using the unweighted pair group method using arithmetic averages (UPGMA) method. Abbreviations indicate species composition of clusters. $\mathrm{A}=P$. abappressorium; $\mathrm{D}=P$. debaryanum; $\mathrm{E}=$ Pythium sp. (aff. echinulatum), $\mathrm{H}=P$. heterothallicum; $\mathrm{O}=$ P. oligandrum; $\mathrm{R}=P$. rostratum; and $\mathrm{U}=P$. ultimum. 
with $P$. heterothallicum and $P$. sp. (aff. echinulatum) (Cluster 2), $P$. heterothallicum in association with $P$. sp. (aff. echinulatum) (Cluster 3 ), and $P$. rostratum in association with $P$. ultimum (Cluster 4 ).

Relationships among environmental zones and Pythium communities. Soil type and annual precipitation were highly correlated $(r=0.869, P=0.000)$, but average annual temperature and soil type $(r=0.164)$ and temperature and precipitation $(r=$ -0.071 ) were not correlated. CCA identified three axes (Fig. 4 and 5). Axis 1 was highly correlated with soil and precipitation, and axis 2 and 3 were most correlated with temperature (Table 1). The eigenvalues of each axis were low (Table 2), explaining only 4.8, 1.9 , and $1.2 \%$ of the variation for axis 1,2 , and 3 , respectively. Eigenvalues represent the variance in the community matrix that is attributed to a particular axis. A Monte-Carlo randomization test of the eigenvalues showed that less than $3 \%$ of the 1,000 runs were greater than the observed values (Table 2). There was a significant correlation between sample scores for an axis derived from the species data and the sample scores that are linear combinations of the environmental variables (Table 3). For example, on axis 1 , which was correlated with soil and precipitation, $P$. ultimum and $P$. abappressorium were separated in a direction opposite from that of $P$. heterothallicum (Fig. 4); the rest of the species clustered toward the origin (center of graph). On axis 2, which showed the strongest correlation with temperature, $P$. debaryanum was separated from $P$. oligandrum. On axis 3 , which had the strongest correlation with temperature, $P$. ultimum and $P$. rostratum were separated in the opposite direction compared to the rest of the species (Fig. 5).

Four of the communities were not distributed as expected among the environmental classes. The $P$. abappressorium-oligandrum-ultimum community (Cluster 1B) was more predominant in lighter (courser-textured) soils (L3) and drier precipitation zones (300 to $400 \mathrm{~mm}$ per year) (Table 4 ). The $P$. debaryanum and $P$. heterothallicum communities were more predominant than expected in the heavier (finer-textured) soils (L5) and zones with higher precipitation (500 to $600 \mathrm{~mm}$ ). The $P$. rostratum-ultimum

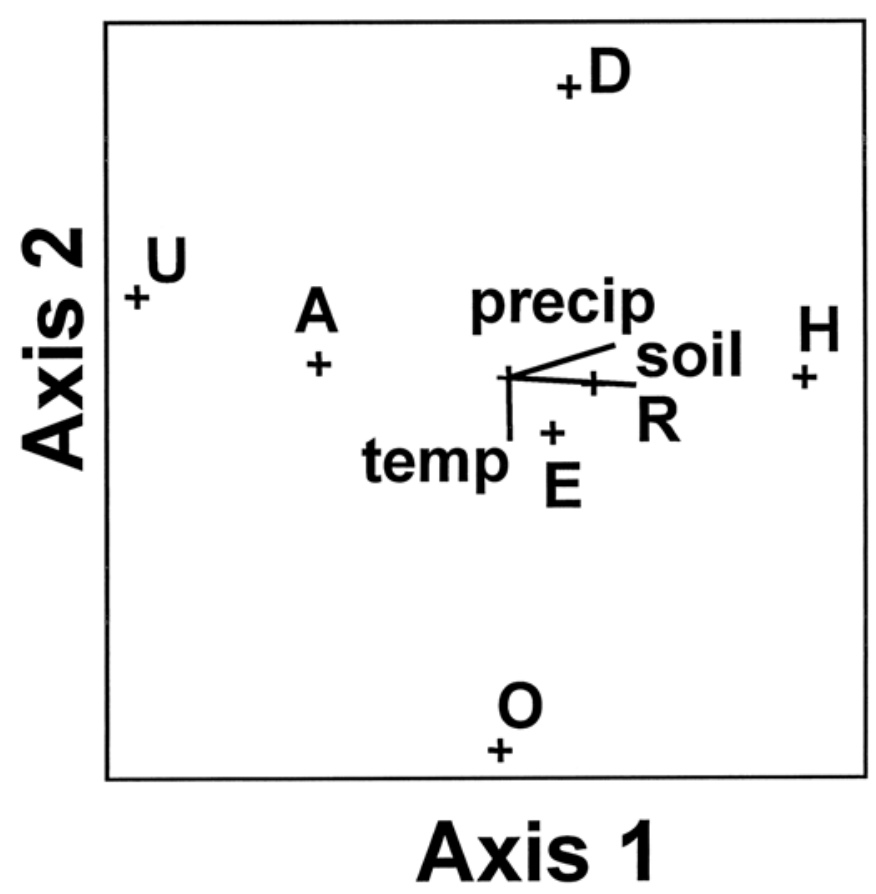

Fig. 4. Biplot from canonical correspondence analysis showing relationship between Pythium species and environmental factors (soil type, average annual precipitation, and average annual temperature) along Axis 1 and 2. Solid lines represent variable vectors. $\mathrm{A}=P$. abappressorium; $\mathrm{D}=P$. debaryanum; $\mathrm{E}=$ Pythium $\mathrm{sp}$. (aff. echinulatum), $\mathrm{H}=P$. heterothallicum; $\mathrm{O}=$ $P$. oligandrum $; \mathrm{R}=P$. rostratum; and $\mathrm{U}=P$. ultimum. community was strongly associated with the higher average annual temperature zone of $9-10^{\circ} \mathrm{C}$.

\section{DISCUSSION}

This work is the first to show the species composition of Pythium communities in dryland wheat fields over a wide geographical area $\left(27,000 \mathrm{~km}^{2}\right)$ encompassing a range of soil, precipitation, and temperature zones. From the 80 sites, a total of 46 different species combinations were detected. This species variability may be due to sampling error or limits in detection, i.e., more species may be present but were not detected. From one to six species of Pythium were isolated from each site, which is less than the modal number of four to six species per site found by Dick and Ali-Shtayeh (9). Similarly, a small number of Pythium species predominated at each site in a survey of commercial alfalfa fields (15). In our survey, the most dominant species was the newly described $P$. abappressorium, which was isolated from half of the sites (37). This species forms small, plerotic oospores and spherical sporangia within appressoria with the remnants of the appressoria often remaining attached to reproductive structures in older cultures. This species was also isolated from apple roots in central Washington (31), being called Pythium MMI (aff. Macrosporum), but was shown to have ITS-1 sequences identical to $P$. abappressorium (C. A. Lévesque, personal communication). Pythium MMI was not pathogenic to apple, but precolonization of apple roots with this isolate provided biological control against pathogenic $P$. ultimum and $P$. sylvaticum (31).

It is unclear why $P$. abappressorium was not found in a previous survey of fields around Pullman, WA and Moscow, ID (4). P. abappressorium could have been mistaken for asexual forms of $P$. ultimum since both form similar-looking hyphal swellings. Chamswarng and Cook (4) found isolates of P. aristosporum Drechs., $P$. ultimum var. ultimum, $P$. ultimum var. sporangiiferum, $P$. irregulare, $P$. torulosum Coker \& Patterson, P. sylvaticum, $P$. volutum Vanterpool, $P$. heterothallicum and two unidentified

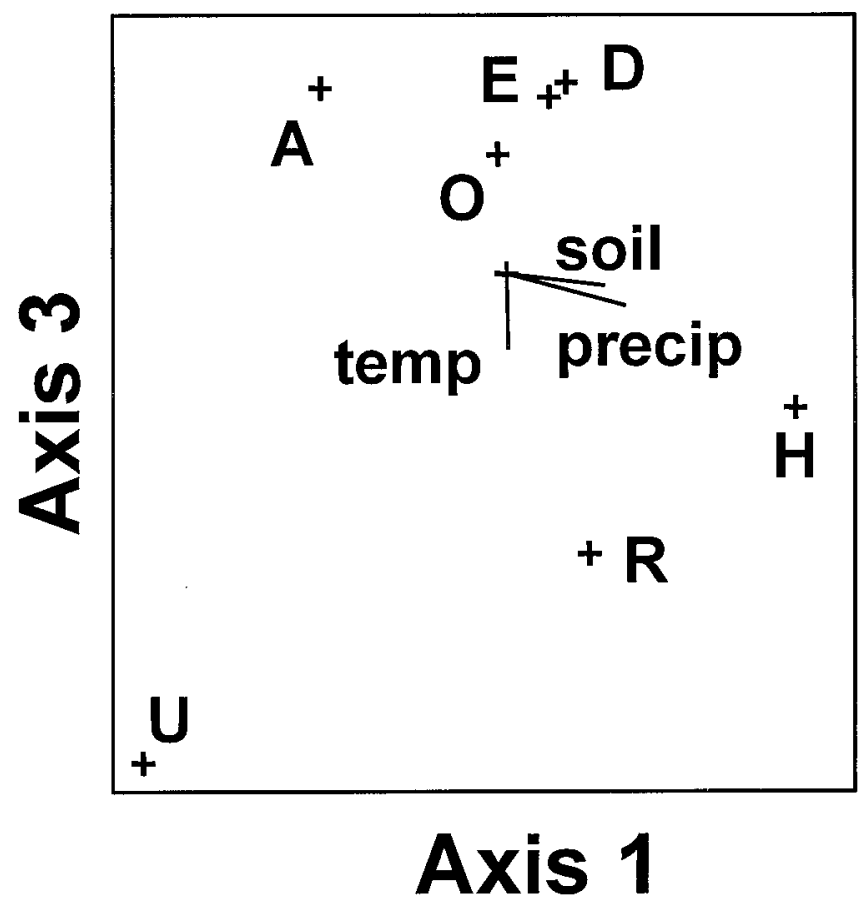

Fig. 5. Biplot from canonical correspondence analysis showing relationship between Pythium species and environmental factors (soil type, average annual precipitation, and average annual temperature) along Axis 1 and 3 . Solid lines represent variable vectors. $\mathrm{A}=P$. abappressorium; $\mathrm{D}=P$. debaryanum $; \mathrm{E}=$ Pythium $\mathrm{sp}$. (aff. echinulatum) $\mathrm{H}=P$. heterothallicum $; \mathrm{O}=$ $P$. oligandrum $; \mathrm{R}=P$. rostratum $;$ and $\mathrm{U}=P$. ultimum. 
species, referred to as Pythium sp. "E" and "D". P. debaryanum was common in our survey but absent from the previous survey of Chamswarng and Cook (4). It may have been classified as $P$. irregulare or $P$. ultimum in the previous survey since the key of van der Plaats-Niterink (42) did not recognize P. debaryanum as a valid species and these three species are morphologically similar. The low frequency of $P$. sylvaticum and $P$. irregulare in our survey is also in contrast with the results of surveys of Chamswarng and Cook (4) and the work of Pankhurst et al. (35), who found $P$. irregulare to be the dominant species in wheat field soils in south Australia. In a survey of Pythium spp. on perennial grasses, $P$. irregulare-debaryanum, $P$. torulosum, and heterothallic forms were the most predominant of 431 isolates (18). P. rostratum was common in our survey, but it was not detected by Chamswarng and Cook (4). Sprague (39) specifically mentioned $P$. rostratum as having been found in the Pullman, WA area. Our isolates of $P$. rostratum did not completely match the type species based on ITS-1 sequences, but it closely resembled this species based on its morphological description. Mazzola et al. (31) isolated an identical fungus based on ITS-1 sequences, which they termed Pythium MM4 (aff. rostratum).

P. ultimum was isolated only from roughly $20 \%$ of the sites. Chamswarng and Cook (4) found P. ultimum made up less than $5 \%$ of isolates from a single site. The sporangia of our Pythium sp. (aff. echinulatum) resemble those labeled by Chamswarng and Cook (4) as Pythium sp. "E" and described as heterothallic (did not form oospores in single culture). However, we were unable to induce oospore formation in Pythium sp. (aff. echinulatum), even with limited pairing of isolates.

Based on limited virulence testing of isolates from our survey, $P$. ultimum, $P$. debaryanum, and $P$. irregulare were the most virulent, causing significant damping-off of wheat, followed by $P$. abappressorium and $P$. rostratum (R. Higginbotham, T. Paulitz, and K. Kidwell, unpublished data). P. heterothallicum and Pythium sp. (aff. echinulatum) did not cause damping-off but did reduce root biomass of wheat. Ingram and Cook (19) found that $P$. ultimum and $P$. irregulare significantly reduced emergence and length of the first true leaf of wheat and that $P$. heterothallicum was only weakly pathogenic.

$P$. graminicola and $P$. arrhenomanes have been implicated in root rot of wheat in the United Kingdom (46) and in the North American Great Plains of the United States (44). P. arrhenomanes is also pathogenic on oats and barley (22) and is one of the most prevalent and aggressive pathogens of turfgrass (1). However,

TABLE 1. Intraset correlation and biplot scores between environmental factors and axes of canonical correspondence analysis

\begin{tabular}{lccl}
\hline & \multicolumn{3}{c}{ Correlations (biplot scores) } \\
\cline { 2 - 4 } Variable & Axis 1 & Axis 2 & Axis 3 \\
\hline Soil & 0.982 & -0.113 & -0.150 \\
& $(0.295)$ & $(-0.022)$ & $(-0.023)$ \\
Precipitation & 0.873 & 0.350 & -0.339 \\
& $(0.262)$ & $(0.067)$ & $(-0.051)$ \\
Temperature & -0.019 & -0.772 & -0.635 \\
& $(-0.006)$ & $(-0.147)$ & $-0.095)$ \\
\hline
\end{tabular}

TABLE 2. Eigenvalues from matrix used in canonical correspondence analysis

\begin{tabular}{lcccccc}
\hline & \multicolumn{2}{c}{ Real data } & & \multicolumn{4}{c}{ Randomized data Monte Carlo test } \\
\cline { 2 - 2 } \cline { 5 - 7 } Axis & Eigenvalue & & Mean & Minimum & Maximum & $P^{\mathrm{a}}$ \\
\hline 1 & 0.090 & & 0.040 & 0.011 & 0.101 & 0.007 \\
2 & 0.036 & & 0.018 & 0.001 & 0.051 & 0.030 \\
3 & 0.023 & & 0.006 & 0.000 & 0.027 & 0.005 \\
\hline
\end{tabular}

${ }^{a} P=$ proportion of randomized runs with eigenvalue greater than or equal to the observed eigenvalue, i.e., $P=1+$ no. permutations $>=\operatorname{observed} /(1+$ no. permutations). Monte Carlo test based on 999 runs. these pathogens have been notably absent in surveys of wheat in the dryland Pacific Northwest (PNW). One notable distinction is that the climate of the PNW is Mediterranean, with warm, dry summers, unlike the other areas that receive considerable precipitation during the summer growing season.

Two other considerations must be taken in interpreting this survey: the time of sampling and the method of isolation. We sampled toward the end of the growing season in July and August when soil conditions were fairly dry, unlike Chamswarng and Cook (4), who sampled in the fall and spring. We also baited with grass leaves, which may provide a wider diversity of Pythium spp. than methods that isolate directly from wheat roots or from soil dilution plates, especially those species that are weakly or nonpathogenic on wheat. It is difficult to isolate Pythium spp. from roots of mature wheat plants because diseased roots are rotted away and not recovered during root washing and due to competition from secondary colonists. Before baiting, we wetted and incubated the soils for a few days so our isolations probably reflect the species of Pythium that would be active at the start of the wet season, when winter wheat is planted in the fall. By collecting all the samples from dry soil and roots toward the end of the season, we also avoided the confounding factor of time of isolation from living roots. For example, some species may be more dominant from roots in the late fall-early spring, but less dominant later in the season. If samples were collected over a range of times, it would be difficult to compare among sites.

Few studies have examined the composition of Pythium communities in soil, especially over a large area. Dick and AliShtayeh (9) examined communities of Pythium spp. in 38 farmland and parkland sites near Reading, England, but their study was done on a number of soil types over a small geographical area. They identified a number of communities with cluster analysis and found that land management (e.g., cultivation practices) had a greater influence than cropping sequence. In their study, Pythium intermedium and asexual Pythium spp. with hyphal swellings were the most abundant species. In our work, cluster analysis based on Jaccard's similarity coefficient defined six distinct com-

TABLE 3. Species-environment correlations from canonical correspondence analysis

\begin{tabular}{lcccccc}
\hline & \multicolumn{2}{c}{ Real data } & & \multicolumn{4}{c}{ Randomized data Monte Carlo test } \\
\cline { 2 - 2 } \cline { 5 - 7 } Axis & Spp-Envt. Corr. & & Mean & Minimum & Maximum & $P^{\mathrm{a}}$ \\
\hline 1 & 0.483 & & 0.345 & 0.182 & 0.527 & 0.016 \\
2 & 0.352 & & 0.231 & 0.054 & 0.409 & 0.015 \\
3 & 0.248 & & 0.135 & 0.022 & 0.309 & 0.016 \\
\hline
\end{tabular}

a $P=$ proportion of randomized runs with eigenvalue greater than or equal to the observed eigenvalue, i.e., $P=1+$ no. permutations $>=$ observed $/(1+$ no. permutations). Monte Carlo test based on 999 runs.

TABLE 4. Environmental classification of Pythium communities according to soil type, precipitation, and temperature zones in eastern Washington

\begin{tabular}{lccc}
\hline & \multicolumn{3}{c}{ Environmental variable } \\
\cline { 2 - 4 } Community & Soil type & Precipitation & Temperature \\
\hline $\begin{array}{l}\text { P. abappressorium- } \\
\quad \text { debaryanum }\end{array}$ & $3.9(4)^{\mathrm{a}}$ & $3.7(4)$ & $8.1(8)$ \\
$\begin{array}{l}P \text {. abappressorium- } \\
\quad \text { oligandrum-ultimum }\end{array}$ & $3.3(3)^{* \mathrm{~b}}$ & $3.2(3)^{*}$ & $8.0(8)$ \\
$\begin{array}{l}P . \text { abappressorium-rostratum } \\
P . \text { debaryanum }\end{array}$ & $4.5(5)$ & $4.0(4)$ & $8.6(8)$ \\
$\begin{array}{l}\text { P. heterothallicum } \\
P . \text { rostratum-ultimum }\end{array}$ & $4.7(5)^{*}$ & $4.5(5)^{*}$ & $8.0(8)^{*}$ \\
Mean & $4.8(5)^{*}$ & $4.4(4)^{*}$ & $8.3(8)$ \\
\hline
\end{tabular}

a Average and median (in parentheses) values for each environmental variable where each Pythium spp. occurred.

$\mathrm{b} *$ denotes that the frequency distribution is significantly different from the expected $(P<0.05)$, based on Chi-Square approximation of two-tailed Kolmogorov-Smirnov statistic. 
munities of Pythium spp. Three communities contained P. abappressorium, which was found in similar frequencies across all environmental zones. However, one subcommunity, P. abappressorium in association with $P$. oligandrum and $P$. ultimum did not fit the expected distribution, but was more predominant in coarsertextured soil and drier precipitation zones. Hancock (15) found a similar correlation with Pythium ultimum on alfalfa roots and soil temperature, with $P$. ultimum being more predominant in the warmer summer months. In our work, a Chi-square test showed a significant association between $P$. oligandrum and P. ultimum. This may be due to a mycoparasitic relationship (2) between the two fungi, or because they are adapted to similar environments. Two communities dominated by $P$. debaryanum and $P$. heterothallicum, respectively, were more prevalent than expected in the wetter precipitation zones and finer-textured soils. $P$. debaryanum and $P$. sp. (aff. echinulatum) were not detected in soil zone L2 and Pythium sp. (aff. echinulatum) and $P$. heterothallicum were not found in zones with 200 to $300 \mathrm{~mm}$ of precipitation per year. $P$. heterothallicum does not form oospores in single culture and may reproduce asexually in the field without a resistant oospore to survive drier conditions. $P$. debaryanum produces oospores readily. On the other hand, $P$. ultimum was found at a higher frequency in courser-textured, drier soils in the western part of the sampling zone, compared to the wetter finer-textured soils in the eastern part. These same trends were evident graphically in the biplot of the CCA. P. ultimum and $P$. abappressorium were separated in opposite directions from $P$. debaryanum and $P$. heterothallicum on axis 1 , which was highly correlated with both soil type and precipitation. Both soil type and precipitation were also highly correlated with each other due to the prevailing weather patterns in the region, increasing clay content with increasing annual precipitation. The precipitation gradient is due to the rain shadow of the Cascade Mountains, with more precipitation to the east. The prevailing wind direction also runs west to east, so over thousands of years, larger soil particles were deposited in the western part of the sampling area with smaller soil particles in the eastern part. However, one confounding factor should be considered. In the lower rainfall zones, farmers practice a winter wheat-summer fallow rotation, where the field is not cropped every other year to accumulate soil moisture for the winter wheat. In addition, the fallow is often maintained with extensive cultivation using a rod weeder, which pulverizes the soil into a fine powder to break the capillary connection with the lower soil and inhibit soil water loss by evaporation. Farmers in the wetter areas practice annual cropping, often with a winter wheat wheat-spring barley-spring pea rotation. These differences in management practices may also influence the makeup of Pythium communities.

Other studies have similarly shown a correlation between environmental factors and Pythium spp. On alfalfa, P. ultimum and $P$. irregulare were often together and positively correlated with average rainfall (23). Conversely, $P$. sylvaticum was negatively correlated with rainfall and seemed to be associated with higher temperatures and drier conditions (23). However, this was based on only two field sites over 2 years. Soil texture differences have been associated with differences in Pythium activity. In the San Joaquin Valley of California, finer-textured silty clay and silty clay loams tended to be more suppressive to $P$. ultimum than coarser clay loam soils (29). However, soil texture alone was not responsible for this difference, which was attributed to the activity of $P$. oligandrum, which was more tolerant of high $\mathrm{Cl}$ levels and could compete saprophytically with $P$. ultimum. Hancock and Grimes (16) found a seasonal variation with Pythium on alfalfa in California, with $P$. ultimum being more prevalent in the summer and $P$. irregulare in cooler spring.

In conclusion, a number of Pythium communities and species associations were detected in wheat-field soils in eastern Washington and these were associated with environmental gradients across this region. $P$. abappressorium was detected at the most sites and was widely distributed across all soil, precipitation, and temperature zones, while other communities dominated by species such as $P$. debaryanum, $P$. heterothallicum, and $P$. sp. (aff. Echinulatum) were more frequent in wetter zones with finer-textured soils. Despite the detectible influence of environmental gradients on species composition, these three variables explained less than $10 \%$ of the variance in the sampled communities. Further work is needed to examine the temporal dynamics of Pythium communities, to see if these associations are present at other times of the year. Crop rotation and tillage practices may also drive the succession of these communities over time.

\section{ACKNOWLEDGMENTS}

We thank N. J. Grünwald (USDA-ARS, Prosser, WA) for assistance with multivariate data analysis, helpful suggestions, and review of the manuscript; C. A. Lévesque (Agriculture and Agri-Foods Canada, Ottawa, ON) for access to his database of Pythium ITS sequences; and F. Dugan and R. J. Cook for review of the manuscript. This work was partially supported by a grant from the O. A. Vogel Wheat Research Fund.

\section{LITERATURE CITED}

1. Abad, Z. G., Shew, H. D., and Lucas, L. T. 1994. Characterization and pathogenicity of Pythium species isolated from turfgrass with symptoms of root and crown rot in North Carolina. Phytopathology 84:913-921.

2. Berry, L. A., Jones, E. E., and Deacon, J. W. 1993. Interaction of the mycoparasite Pythium oligandrum with other Pythium species. Biocontrol Sci. Technol. 3:247-260.

3. Boling, M., Frazier, B., and Busacca, A. 1998. General Soil Map of Washington. Washington State University Press, Pullman.

4. Chamswarng, C., and Cook, R. J. 1985. Identification and comparative pathogenicity of Pythium species from wheat roots and wheat-field soils in the Pacific Northwest. Phytopathology 75:821-827.

5. Cook, R. J., Sitton, J. W., and Haglund, W. A. 1987. Influence of soil treatments on growth and yield of wheat and implications for control of Pythium root rot. Phytopathology 77:1172-1198.

6. Cook, R. J., Sitton, J. W., and Waldher, J. T. 1980. Evidence for Pythium as a pathogen of direct-drilled wheat in the Pacific Northwest. Plant Dis. 64:1061-1066.

7. Cook, R. J., and Veseth, R. J. 1991. Wheat Health Management. The American Phytopathological Society, St. Paul, MN.

8. Dick, M. W. 1990. Key to Pythium. Published by author. Reading, U.K.

9. Dick, M. W., and Ali-Shtayeh, M. S. 1986. Distribution and frequency of Pythium species in parkland and farmland soils. Trans. Br. Mycol. Soc. 86:49-62.

10. Didden, W. A. M., Marinissen, J. C. Y., Vreeken-Buijs, M. J., Burgers, S. L. G. E., Fluiter, R. de, Geurs, M., and Brussaard, L. 1994. Soil mesoand macrofauna in two agricultural systems: Factors affecting population dynamics and evaluation of their role in carbon and nitrogen dynamics. Agri. Ecosystem. Environ. 51:171-186.

11. Drijber, R. A., Doran, J. W., Parkhurst, A. M., and Lyon, D. J. 2000. Changes in soil microbial community structure with tillage under longterm wheat-fallow management. Soil Biol. Biochem. 32:1419-1430.

12. Farr, D. F., Bills, G. F., Chamuris, G. P., and Rossman, A. Y. 1989. Fungi on Plants and Plant Products in the United States. The American Phytopathological Society, St. Paul, MN.

13. Grünwald, N. J., Hu, S., and van Bruggen, A. H. C. 2000. Short-term cover crop decomposition in organic and conventional soils: Characterization of soil C, N, microbial and plant pathogen dynamics. Eur. J. Plant Pathol. 106:37-50.

14. Grünwald, N. J., Hu, S., and van Bruggen, A. H. C. 2000. Short-term cover crop decomposition in organic and conventional soils: Soil microbial and nutrient cycling indicator variables associated with different levels of soil suppressiveness to Pythium aphanidermatum. Eur. J. Plant Pathol. 106:51-65.

15. Hancock, J. G. 1985. Fungal infection of feeder rootlets of alfalfa. Phytopathology 75:1112-1120.

16. Hancock, J. G., and Grimes, D. W. 1990. Colonization of rootlets of alfalfa by species of Pythium in relation to soil moisture. Phytopathology 80:1317-1322.

17. Hassink, J., Voshaar, J. H. O., Nijhuis, E. H., and van Veen, J. A. 1991. Dynamics of the microbial populations of a reclaimed-polder soil under a conventional and a reduced-input farming system. Soil Biol. Biochem. 23:515-524.

18. Hendrix, F. F., and Campbell, W. A. 1970. Distribution of Phytophthora and Pythium species in soils in the continental United States. Can. J. Bot. 
48:377-384.

19. Ingram, D. M., and Cook, R. J. 1990. Pathogenicity of four Pythium species to wheat, barley, peas and lentils. Plant Pathol. 39:110-117.

20. James, F. C., and McCulloch, C. E. 1990. Multivariate analysis in ecology and systematics: Panacea or pandora's box? Annu. Rev. Ecol. Syst. 21:129-166.

21. Kageyama, K., Ohyama, A., and Hyakumachi, M. 1997. Detection of Pythium ultimum using polymerase chain reaction with species-specific primers. Plant Dis. 81:1155-1160.

22. Kilpatrick, R. A. 1968. Seedling reaction of barley, oats and wheat to Pythium species. Plant Dis. Rep. 52:209-212.

23. Larkin, R. P., English, J. T., and Mihail, J. D. 1995. Identification, distribution and comparative pathogenicity of Pythium spp. associated with alfalfa seedlings. Soil Biol. Biochem. 27:357-364.

24. Lévesque, C. A., Harlton, C. E., and de Cock, A. W. A. M. 1998. Identification of some oomycetes by reverse dot blot hybridization. Phytopathology 88:213-222.

25. Lévesque, C. A., Vrain, T. C., and De Boer, S. H. 1994. Development of a species-specific probe for Pythium ultimum using amplified ribosomal DNA. Phytopathology 84:474-478.

26. Ludwig, J. A., and Reynolds, J. F. 1988. Statistical Ecology: A Primer on Methods and Computing. John Wiley and Sons, NY.

27. Magurran, A. E. 1988. Ecological Diversity and Its Measurement. Princeton University Press, Princeton, NJ.

28. Marcos, J. 2000. Simulation-based assessment of alternative crops in the dryland Pacific Northwest. Ph.D. diss. Washington State University, Pullman.

29. Martin, F. N., and Hancock, J. G. 1986. Association of chemical and biological factors in soils suppressive to Pythium ultimum. Phytopathology 76:1221-1231.

30. Matthews, V. D. 1931. Studies on the Genus Pythium. University of North Carolina Press, Chapel Hill, NC.

31. Mazzola, M., Andrews, P. K., Reganold, J. P., and Lévesque, C. A. 2002. Frequency, virulence, and metalaxyl sensitivity of Pythium spp. isolated from apple roots under conventional and organic production systems. Plant Dis. 86:669-675.

32. Middleton, J. T. 1943. The taxonomy, host range and geographic distribution of the genus Pythium. Mem. Torrey Bot. Club 20:1-171.

33. Mircetich, S. M., and Kraft, J. M. 1973. Efficiency of various selective media in determining Pythium populations in soil. Mycopathol. Mycol. Appl. 50:151-161.

34. Oyarzun, P. J., Dijst, G., and Maas, P. W. T. 1994. Determination and analysis of soil receptivity to Fusarium solani f. sp. pisi causing dry root rot of peas. Phytopathology 84:834-842.

35. Pankhurst, C. E., McDonald, H. J., and Hawke, B. G. 1995. Influence of tillage and crop rotation on the epidemiology of Pythium interactions of wheat in a red-brown earth of South Australia. Soil Biol. Biochem. 27:1065-1073.

36. Paul, B. 2001. ITS region of the rDNA of Pythium longandrum, a new species; Its taxonomy and its comparison with related species. FEMS (Fed. Eur. Microbiol. Soc.) Microbiol. Lett. 202:239-242.

37. Paulitz, T. C., Adams, K., and Mazzola, M. 2003. Pythium abappressorium-a new species from eastern Washington. Mycologia 95:80-86.

38. Sneath, P. H. A., and Sokal, R. R. 1973. Numerical Taxonomy: The Principles and Practice of Numerical Classification. W. H. Freeman and Co., San Francisco, CA.

39. Sprague, R. 1946. Rootrots and leafspots of grains and grasses in the northern Great Plains and western states. Plant Dis. Rep. 163:101-268.

40. Steer, J., and Harris, J. A. 2000. Shifts in the microbial community in rhizosphere and non-rhizosphere soils during the growth of Agrostis stolonifera. Soil Biol. Biochem. 32:869-878.

41. Ter Braak, D. J. F. 1987. Canonical correspondence analysis: A new eigenvector technique for multivariate direct gradient analysis. Ecology 67:1167-1179.

42. Van der Plaats-Niterink, A. J. 1981. Monograph of the genus Pythium. No. 21, Studies in Mycology. Centraalbureau Voor Schimmelcultures, Baarn, the Netherlands.

43. Van der Rooij-Goes, P. C. E. M., van der Putten, W. H., and van Dijk, C. 1995. Analysis of nematodes and soil-borne fungi from Ammophila arenaria (Marram grass) in Dutch coastal foredunes by multivariate techniques. Eur. J. Plant Pathol. 101:149-162.

44. Vanterpool, T. C., and Sprague, R. A. 1942. Pythium arrhenomanes on cereals and grasses in the northern Great Plains. Phytopathology 32:327328.

45. Van Tongren, O. F. R. 1995. Cluster analysis. Pages 174-212 in: Data Analysis in Community and Landscape Ecology. R. H. G. Jongman, C. J. F. Ter Braak, and O. F. R. van Tongeren, eds. Cambridge University Press, Cambridge, U.K.

46. Waller, J. M. 1979. Observations on Pythium root rot of wheat and barley. Plant Pathol. 28:17-24.

47. Wang, P. H., and White, J. G. 1997. Molecular characterization of Pythium species based on RFLP analysis of the internal transcribed spacer region of ribosomal DNA. Physiol. Mol. Plant Pathol. 51:129-143.

48. Waterhouse, G. M. 1968. The genus Pythum Pringsheim. Diagnoses (or descriptions) and figures from the original papers. Mycol. Papers, CMI, Kew, Surrey, UK, 110:1-71. 